\title{
Estudo de juntas soldadas à laser de chapas finas de liga com memória de forma NiTi austenítica
}

\author{
Study of laser welded joints of thin sheets of austenitic \\ NiTi shape memory alloy
}

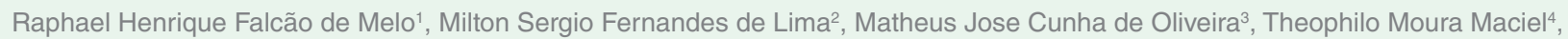
Carlos Jose de Araújo ${ }^{4}$

\section{RESUMO}

Ligas com memória de forma (LMF) de NiTi são materiais inteligentes que possibilitam o desenvolvimento de diversas aplicações de engenharia devido suas propriedades funcionais chamadas de efeito de memória de forma e superelasticidade. No entanto, fabricar componentes com geometria complexa a partir destes materiais é um desafio tecnológico que poderá ser superado com o desenvolvimento de técnicas efetivas de união destas ligas por soldagem. Objetivou-se neste trabalho avaliar os efeitos dos diferentes parâmetros de soldagem nas propriedades mecânicas de juntas soldadas obtidas de chapas finas de uma LMF de NiTi austenítica. As soldagens foram realizadas pelo processo de soldagem à laser (LBW - Laser Beam Welding) variando a potência e velocidade de soldagem e a realização ou não do tratamento térmico pós-soldagem (TTPS). Como ferramenta de otimização foi utilizado um planejamento experimental $2^{3}$ e a metodologia da superfície de resposta. Foi observado que o TTPS promoveu a estabilização de um estado misto de fases na chapa de $\mathrm{NiTi}$, entre a fase $\mathrm{R} e$ a austenita à temperatura ambiente $\mathrm{e}$ que após a soldagem foi possível observar uma redução dos valores aferidos de dureza no metal de solda (MS). Além disso, as juntas soldadas com velocidade de soldagem de $900 \mathrm{~mm} / \mathrm{min}$ e que foram submetidas ao TTPS apresentaram resistência mecânica à tração satisfatória independentemente da potência empregada.

Palavras-chave: Ligas com memória de forma, Ligas de NiTi, Processo de soldagem a laser.

\begin{abstract}
NiTi shape memory alloys (SMA) are smart materials that enable the development of various engineering applications due to their functional properties called shape memory effect and superelasticity. However, to manufacture components with complex geometry from these materials is a technological challenge that can be overcome with the development of effective joint techniques of these alloys by welding. The objective of this work was to evaluate the effects of the different welding parameters on the mechanical properties of welded joints of thin sheets of austenitic NiTi SMA. The joints were performed by the laser welding process varying the power and speed of welding and the influence of post-weld heat treatment (PWHT) was verified. As an optimization and evaluation tool, a design of experiments and the response surface methodology were respectively used. It was observed that the PWHT promoted the stabilization of a phase mixed state in the thin sheet, between the R phase and the austenite at room temperature and that after welding it was possible to observe a reduction of the average values of hardness in the weld metal (WM). Furthermore, welded joints with welding speed of $900 \mathrm{~mm} / \mathrm{min}$ and were submitted to PWHT showed satisfactory tensile mechanical strength independent of the welding power used.
\end{abstract}

Keywords: Shape memory alloys, NiTi alloys, Laser beam welding process.

\footnotetext{
${ }^{1}$ Instituto Federal de Educação, Ciência e Tecnologia da Paraíba - Eixo de Controle e Processos Industriais - Cajazeiras (PB) - Brasil ${ }^{2}$ Instituto de Estudos Avançados - Divisão de Fotônica - São José dos Campos (SP) - Brasil

${ }^{3}$ Instituto Federal de Educação, Ciência e Tecnologia do Ceará - Eixo de Controle e Processos Industriais - Sobral (CE) - Brasil

${ }^{4}$ Universidade Federal de Campina Grande - Centro de Ciências e Tecnologia - Departamento de Engenharia Mecânica - Campina Grande (PB) - Brasil Autor correspondente: Raphael Henrique F. de Melo - Instituto Federal de Educação, Ciência e Tecnologia da Paraíba - Eixo de Controle e Processos Industriais - Rua Jose Antonio da Silva, 300, Jardim Oasis, CEP 58900-000, Cajazeiras (PB) - Brasil (PB) - Brasil

Email: raphael.melo@ifpb.edu.br
}

Recebido: 08/06/2017 Aprovado: 18/07/2017 


\section{INTRODUÇÃO}

Desde sua descoberta em 1932 para uma liga de AuCd, as ligas com memória de forma (LMF) tem possibilitado a concepção de várias aplicações, em função das suas propriedades funcionais especiais de recuperação de grandes deformações pseudo-plásticas, denominadas de efeito de memória de forma (EMF) e superelasticidade (SE). Esse desenvolvimento foi impulsionado em especial com a descoberta das ligas do sistema $\mathrm{NiTi}$, tendo em vista principalmente sua excelente biocompatibilidade e resistência à corrosão ${ }^{(1,2)}$. As aplicações mais conhecidas, tanto para o EMF quanto para a SE, são principalmente em produtos médicos e odontológicos, mas também existem na indústria automotiva, aeroespacial, na construção civil e no setor de óleo e gás ${ }^{(3)}$. Estes fenômenos estão associados a uma transformação de fase não-difusional no estado sólido, do tipo martensítica, cristalograficamente reversível $^{(2)}$. O uso das LMF de NiTi têm crescido também no campo dos sistemas microeletro-mecânicos (micro-electromechanical systems, MEMS) ${ }^{(4)}$, uma vez que as LMF podem ser projetadas para serem um atuador "eletro-termomecânico", que converte energia térmica em um deslocamento acompanhado ou não da realização de um trabalho mecânico. O deslocamento por EMF pode corresponder a uma deformação introduzida, e recuperável por simples aquecimento, de até $8 \%$, contrária e muitíssimo superior a dilatação térmica comumente verificada em ligas metálicas convencionais. Atualmente existem três grandes grupos de LMF que vem sendo estudadas: base NiTi, base cobre e base ferro ${ }^{(2)}$. Este trabalho focará em uma LMF de NiTi.

Devido a dificuldades de conformação mecânica e usinagem das LMF do sistema NiTi, torna-se necessário desenvolver técnicas de união permanente para fabricação de atuadores termomecânicos de geometrias mais complexas ${ }^{(5)}$. Entretanto, o uso de processos convencionais de soldagem por fusão, como os processos GTAW, PAW ou LBW, pode levar a uma perda acentuada da ductilidade ${ }^{(6-8)}$. Este comportamento se deve a formação de eutéticos de baixo ponto de fusão no metal de solda (MS), que promovem a formação de trincas de solidificação associadas à microestrutura dendrítica do MS e a precipitação de fases deletérias como Ni4Ti3, Ni3Ti2, Ni3Ti e NiTi2 na zona termicamente afetada (ZTA) da junta ${ }^{(9)}$.

Espera-se que as barreiras existentes para a comercialização de produtos com geometria complexa baseados em LMF possam ser reduzidas pelo desenvolvimento de processos efetivos de união ${ }^{(10)}$. O processo LBW, apesar do seu maior custo inerente, é o mais utilizado para produzir juntas soldadas de LMF de $\mathrm{NiTi}^{(4,6,9,10-30)}$. No entanto, a maior parte dos trabalhos publicados além de fazerem uso do processo LBW, correspondem a união de fios finos de LMF NiTi (diâmetros até $1 \mathrm{~mm})^{(4,23-26,30)}$. Existem poucos trabalhos realizados com chapas finas (espessuras entre $0,5 \mathrm{~mm}$ e $1 \mathrm{~mm}$ ) de LMF NiTi, a maior parte deles sendo bastante recentes $^{(19-22,27,30)}$.
Neste contexto, este trabalho tem por objetivo avaliar a união de chapas finas de LMF de NiTi, no estado austenítico, pelo processo de soldagem LBW. Busca-se fundamentalmente verificar a influência dos parâmetros de processo e a influência do tratamento térmico pós-soldagem na resistência mecânica das juntas similares NiTi-NiTi por meio de ensaios de tração, além de determinar a influência destes parâmetros nas temperaturas de transformação de fase, microdureza e microestrutura.

\section{MATERIAIS E MÉTODOS}

Neste trabalho foram utilizadas chapas finas de LMF de NiTi com $0,8 \mathrm{~mm}$ de espessura. Na Tabela 1 é apresentada a composição química em peso da liga segundo o fornecedor (Sunrise Titanium Technology Co., China).

Tabela 1: Composição química em peso da LMF de NiTi.

\begin{tabular}{c|c|c|}
\hline Material & Ti (\%) & Ni (\%) \\
\hline $\begin{array}{c}\text { Chapa A - Estado } \\
\text { Austenítico }\end{array}$ & 44,09 & 55,91 \\
\hline
\end{tabular}

Na Fig. 1 são apresentadas as curvas de análise térmica em DSC. Em ambos os casos, os resultados são para as chapas na condição como recebida ou sem tratamento térmico (STT) e

A

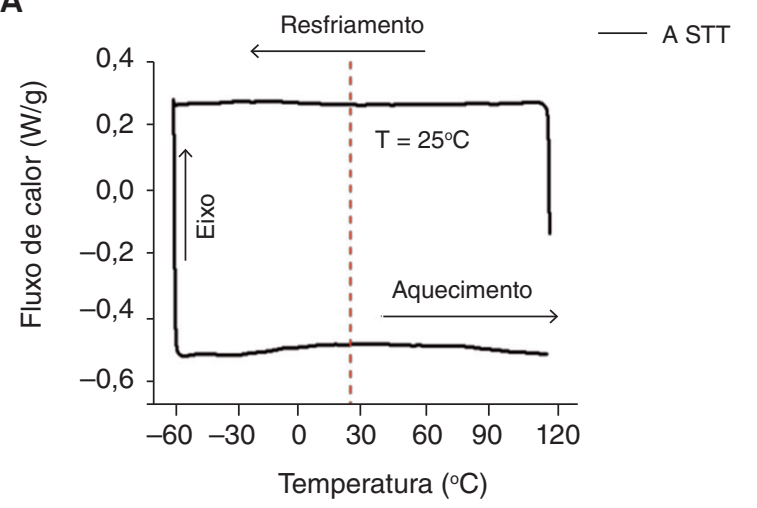

B

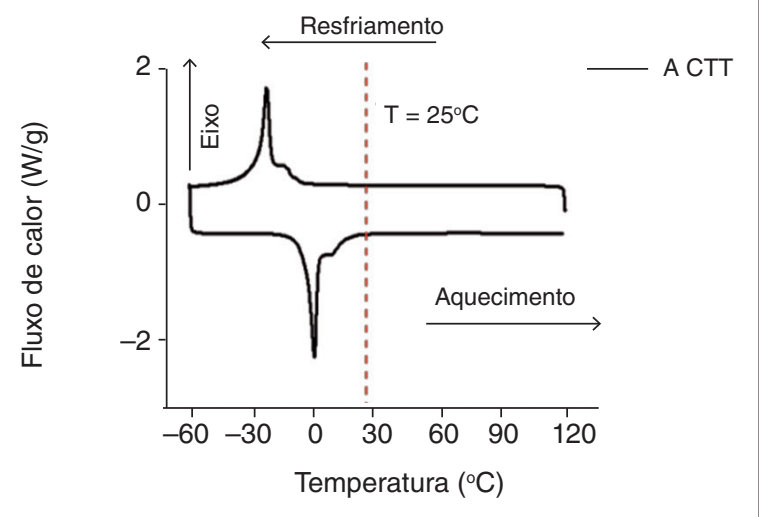

Figura 1: Curva de ensaio DSC para a chapa A na condição como recebida $(A)$ e na condição tratada termicamente a $500^{\circ} \mathrm{C}$ por uma hora e resfriada em óleo (B). 
tratadas termicamente $(\mathrm{CTT})$ a $500^{\circ} \mathrm{C}$ por uma hora, com o intuito de "desbloquear" a transformação de fase das chapas de LMF de NiTi.

É possível verificar na Figura 1a que não existem picos bem definidos na curva de análise térmica em DSC, indicando que praticamente não ocorrem transformações de fase na faixa de temperatura avaliada $\left(+120^{\circ} \mathrm{C}\right.$ a $\left.-60^{\circ} \mathrm{C}\right)$. Após a realização do tratamento térmico, Figura $1 \mathrm{~b}$, a curva de análise térmica em DSC apresenta picos característicos indicando que as transformações de fase foram desbloqueadas, estabilizando a austenita na temperatura de aproximadamente $25^{\circ} \mathrm{C}$. Constata-se também a existência da fase $\mathrm{R}$, caracterizada pelo pequeno pico durante $\mathrm{o}$ resfriamento a temperaturas próximas de $-15^{\circ} \mathrm{C}$. O tratamento térmico é responsável por consumir $\mathrm{Ni}$ da matriz do material, e como o Ni é o elemento responsável por estabilizar a austenita a temperaturas próximas a ambiente, o seu empobrecimento na matriz pode resultar em aumento das temperaturas de transformação de fase $\mathrm{e}^{(2)}$.

O laser de Ytterbium $(\mathrm{Yb})$ à fibra utilizado neste trabalho para obter as juntas soldadas a partir das chapas da LMF NiTi está instalado no Laboratório Multiusuário de Desenvolvimento e Aplicações de Lasers e Óptica (DedALO), do Instituto de Estudos Avançados (IEAv/CTA) em São José dos Campos (São Paulo). Trata-se de um laser de $2 \mathrm{~kW}$ de potência média (IPG, modelo YLR-2000) dotado de uma fibra de saída de $50 \mu \mathrm{m}$ e 5 metros de extensão. Os experimentos de soldagem foram realizados em uma mesa de comando numérico computadorizada (CNC), controlada por computador por meio de software EMC2.

Para avaliar as variáveis de processo LBW, foi utilizada a técnica do planejamento experimental fatorial em dois níveis com uma réplica de todas as condições de soldagem, uma vez que foram utilizadas também variáveis qualitativas, impedindo a rotação destas variáveis em torno de um ponto central. A réplica de todas as condições de soldagem é utilizada para estimar o erro e as incertezas envolvidas. Os valores desses níveis encontram-se resumidos na Tabela 2. Estes parâmetros foram determinados após longa varredura exploratória de condições de soldagem adequadas. O foco do feixe laser foi mantido constante, com distância focal de $92 \mathrm{~mm}$ (distância lente-peça), sobre a superfície do material, o que equivale a um diâmetro de feixe de $151 \mu \mathrm{m}$. As soldagens não contaram com gás de proteção, devido ao caráter pirofórico do material observado durante os testes preliminares. Estes procedimentos permitiram definir o intervalo de parâmetros

Tabela 2: Níveis reais e codificados dos fatores para o processo LBW.

\begin{tabular}{|c|c|c|}
\hline \multirow{2}{*}{ Variáveis de entrada (k) } & \multicolumn{2}{|c|}{ Níveis } \\
\cline { 2 - 3 } & -1 & +1 \\
\hline $\mathrm{P}_{\mathrm{m}}(\mathrm{W})$ & 450 & 550 \\
$\mathrm{~V}_{\mathrm{s}}(\mathrm{mm} / \mathrm{min})$ & 900 & 1500 \\
\hline $\begin{array}{c}\text { Tratamento Térmico } \\
\text { Pós-Soldagem }\end{array}$ & STTPS & CTTPS \\
\hline
\end{tabular}

ótimos de processo, associando a qualidade da solda à potência do laser e a velocidade de soldagem. Na Tabela 2, $\mathrm{P}_{\mathrm{m}}$ indica potência média em Watts e $\mathrm{V}_{\mathrm{s}}$ é a velocidade de soldagem em $\mathrm{mm} / \mathrm{min}$, STTPS são as condições em que não foram realizados tratamentos térmicos pós-soldagem e CTTPS são as condições em que foram realizados tratamentos térmicos pós-soldagem. O tratamento térmico pós-soldagem, realizado em forno elétrico, consistiu em um aquecimento até a temperatura de $500^{\circ} \mathrm{C}$ a uma taxa de $20^{\circ} \mathrm{C} / \mathrm{min}$ permanecendo nesta temperatura por duas horas seguido de têmpera em óleo.

A sequência de combinação dos fatores foi definida segundo a ordem padrão descrita na Tabela 3 , com uma réplica de cada experimento. Apesar de a ordem apresentada na Tabela 3 ser a padrão, todos os experimentos foram realizados em ordem aleatória. A réplica dos experimentos permite o cálculo do erro experimental e significância dos efeitos. A sequência aleatória dos experimentos permite a aplicação de testes estatísticos de significância e a construção de intervalos de confiança.

Os ensaios de microdureza foram executados aplicando-se uma carga de 50 gramasforça (gf), por 15 segundos, com espaçamento entre as impressões de $200 \mu \mathrm{m}$. Em cada amostra foram realizadas 40 medidas de microdureza Vickers (HV) ao longo de uma linha horizontal perpendicular ao cordão de solda.

Para determinar as temperaturas de transformação de fase realizou-se uma avaliação da variação da resistência elétrica em função da temperatura (RET), a uma taxa média de variação de temperatura de $4^{\circ} \mathrm{C} / \mathrm{min}$, para uma faixa de temperaturas variando de $-60{ }^{\circ} \mathrm{C}$ a $100^{\circ} \mathrm{C}$, conforme apresentado esquematicamente na Fig. 2. Esses ensaios são realizados usando um banho termostático da marca Huber modelo CC 902, responsável por promover a variação da temperatura, interligado a um sistema de aquisição de dados e uma fonte de corrente elétrica, responsável por promover a diferença de potencial adequada ao ensaio. Essa metodologia de ensaio de RET foi previamente desenvolvida por Reis et al. (2006). O ensaio consiste em aquecer o corpo de prova até o estado de referência austenítico $\left(\mathrm{a} 100^{\circ} \mathrm{C}\right)$, resfriando-o até $-60{ }^{\circ} \mathrm{C}$ e em seguida aquecendo-o ao estado de referência novamente. As medidas de variação da resistência elétrica

Tabela 3: Matriz de experimentos $2^{3}$ mais uma réplica de todas as condições de soldagem.

\begin{tabular}{|c|c|c|c|}
\hline & $\mathrm{P}_{\mathrm{m}}$ & $\begin{array}{c}\text { Velocidade de } \\
\text { Soldagem }\end{array}$ & $\begin{array}{c}\text { Tratamento térmico } \\
\text { pós-soldagem }\end{array}$ \\
\hline $\mathrm{C} 1 / \mathrm{C} 9$ & $450(-1)$ & $900(-1)$ & STTPS $(-1)$ \\
\hline $\mathrm{C} 2 / \mathrm{C} 10$ & $550(+1)$ & $900(-1)$ & STTPS $(-1)$ \\
\hline $\mathrm{C} 3 / \mathrm{C} 11$ & $450(-1)$ & $1500(+1)$ & STTPS $(-1)$ \\
\hline $\mathrm{C} 4 / \mathrm{C} 12$ & $550(+1)$ & $1500(+1)$ & STTPS $(-1)$ \\
\hline $\mathrm{C} 5 / \mathrm{C} 13$ & $450(-1)$ & $900(-1)$ & CTTPS $(+1)$ \\
\hline $\mathrm{C} 6 / \mathrm{C} 14$ & $550(+1)$ & $900(-1)$ & CTTPS $(+1)$ \\
\hline $\mathrm{C} 7 / \mathrm{C} 15$ & $450(-1)$ & $1500(+1)$ & CTTPS $(+1)$ \\
\hline C8/C16 & $550(+1)$ & $1500(+1)$ & CTTPS $(+1)$ \\
\hline
\end{tabular}


foram realizadas de acordo com o esquema da Fig. 3. Esta técnica foi escolhida em detrimento dos ensaios de DSC por se tratar de técnica não destrutiva para determinação das temperaturas de transformação de fase, garantindo uma melhor correlação e verossimilhança entre as propriedades mecânicas observadas e as temperaturas de transformação de fase aferidas e, consequentemente, o estado em que se encontra o material a temperatura ambiente. Além disso, esta é a primeira vez que esta técnica não-destrutiva é utilizada para determinar as temperaturas de transformação de fase em juntas soldadas de LMF de NiTi.

As temperaturas de transformação de fase neste ensaio são determinadas a partir do método das tangentes, como é apresentado esquematicamente na Fig. 4. A intersecção das

Estado de referência (Austenítico)

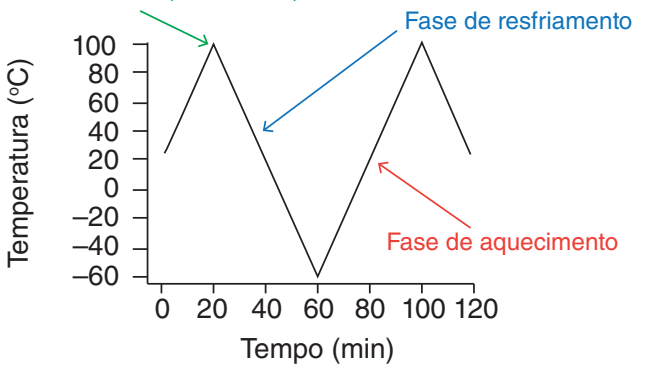

Figura 2: Ciclo térmico de resfriamento e aquecimento no ensaio de RET.

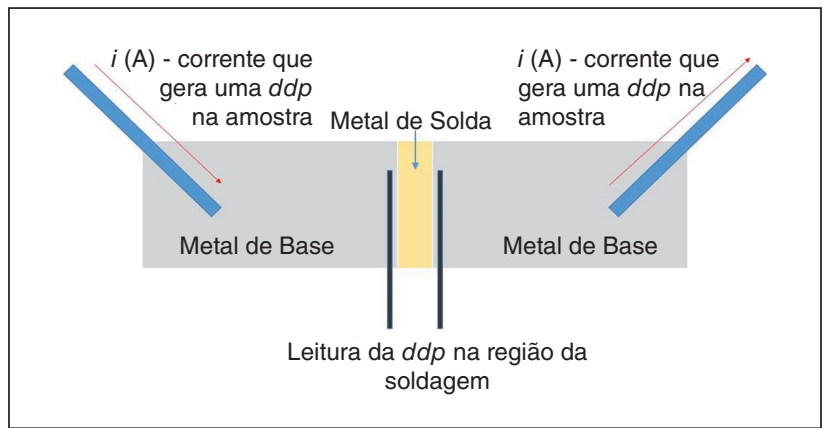

Figura 3: Esquema de medição da queda de tensão para aferição da variação da resistência elétrica junto ao metal de solda.

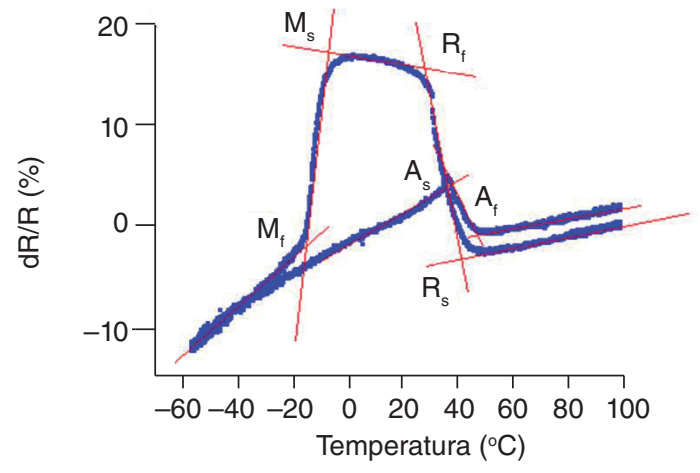

Figura 4: Método das tangentes para determinação das temperaturas de transformação de fase em LMF a partir de um ensaio RET. retas tangentes a curva denota a temperatura em que ocorre a transformação de fase ${ }^{(2)}$.

A caracterização da resistência mecânica das juntas soldadas foi realizada através do ensaio de tração uniaxial, à temperatura ambiente, utilizando-se uma máquina universal de ensaios servohidráulica, marca MTS, modelo 810. O comportamento funcional das juntas soldadas foi avaliado tracionando todas as juntas obtidas em diferentes condições de soldagem até $6 \%$ de deformação a uma taxa de deslocamento de $0,05 \mathrm{~mm} /$ minuto. Ao atingir 6\% de deformação o corpo de prova foi descarregado controladamente (em controle de força) até zerar a carga atuante, adotando o procedimento sugerido na norma ASTM F2516-14. Na Fig. 5 é apresentada a geometria dos corpos de prova utilizados, obtidos por corte em eletroerosão a fio. Foi realizado um ensaio para cada condição de soldagem e sua devida réplica.

Após a realização do carregamento e descarregamento mecânico das juntas soldadas, aquecia-se os corpos de prova (até aproximadamente $100^{\circ} \mathrm{C}$ ) com soprador térmico a fim de recuperar quaisquer deformações remanescentes. Em seguida, cada corpo de prova foi tracionado até a ruptura, utilizando a mesma taxa de deslocamento de $0,05 \mathrm{~mm} /$ minuto.

A caracterização das superfícies de fratura foi realizada via microscopia eletrônica de varredura (MEV), com ampliações de 4000 vezes. Utilizou-se um MEV da marca TESCAN, modelo VEGA 3SBH, equipado com uma sonda da Oxford Instruments para quantificação da composição química via espectroscopia de energia dispersiva (EDS).

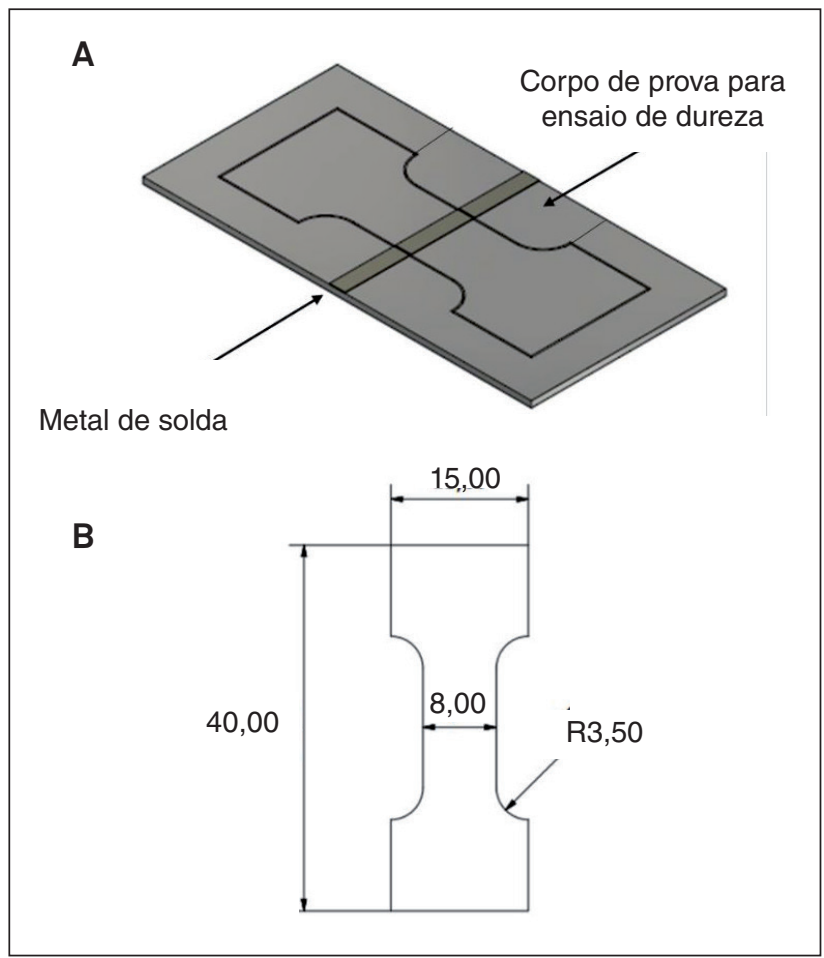

Figura 5: llustração dos corpos de prova de juntas soldadas de LMF NiTi. (A) Esquema da junta soldada indicando o local de onde foi retirado o corpo de prova para ensaio de tração. (B) Dimensões em $\mathrm{mm}$ do corpo de prova para ensaio de tração. 


\section{RESULTADOS E DISCUSSÃO}

Na Fig. 6 são apresentadas as curvas de variação da resistência elétrica em função da temperatura (RET) que permitem determinar as temperaturas das transformações de fase nas juntas soldadas. A temperatura de $100^{\circ} \mathrm{C}$ é tomada como estado de referência para o cálculo da variação da resistência elétrica em todos os casos (para as juntas no estado como soldado e após TTPS). As temperaturas de início e fim de transformação são determinadas a partir da intersecção das retas tangentes, exatamente conforme indicado na Fig. 4.

$\mathrm{O}$ aspecto das curvas na condição como soldado, na Fig. 6a, indica qualitativamente que o material se encontra no estado austenítico, apenas tendendo a iniciar transformação de fase lentamente a partir da temperatura ambiente de $25^{\circ} \mathrm{C}$. Para todas as condições de soldagem (Fig. 6a e Tabela 3) só é possível identificar a temperatura de início de transformação da Fase R (Rs), sendo este comportamento de curva RET similar ao de ligas de NiTi que foram submetidas a laminação e estão com a transformação de fase bloqueada devido ao encruamento característico deste processo de fabricação ${ }^{(2,31)}$. A fase R é um estado de transição entre a fase austenítica e martensítica das LMF de NiTi, caracterizada por apresentar uma estrutura cristalina trigonal com distorção romboédrica no ângulo $\alpha^{(32)}$.

Já o aspecto das curvas de RET correspondentes as condições soldadas e que foram submetidas ao tratamento térmico pós-soldagem (TTPS), Figura 6 b, indica qualitativamenteque todas as juntas soldadas se encontram em um estado misto, entre a fase $\mathrm{R}$ e a fase austenítica, podendo-se determinar as temperaturas de início e fim de transformação da fase R(Rse Rf), da fase martensítica

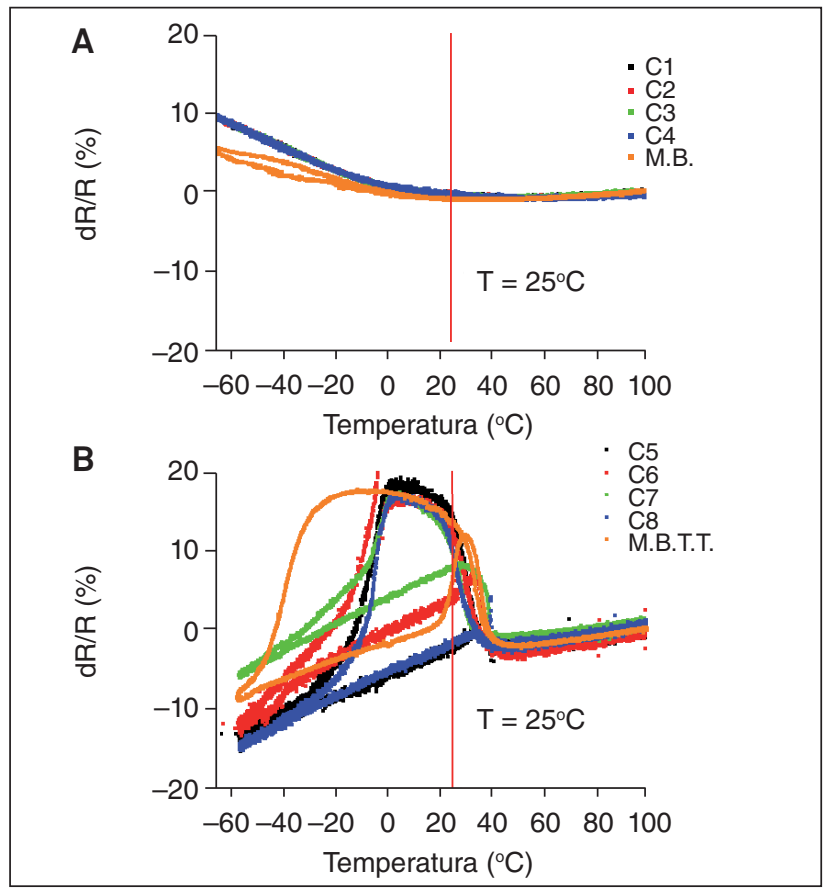

Figura 6: Determinação das temperaturas de transformação de fase via RET das juntas de NiTi nas condições "como soldado" (A) e após TTPS (B).
(Ms e Mf) e da fase austenítica (As e Af), conforme indicado na Fig. 4. Este comportamento é característico de ligas de NiTi que foram submetidas a tratamentos térmicos, pois este inicialmente alivia as tensões residuais oriundas do encruamento promovido pelos processos de laminação (para obtenção das chapas) e de soldagem (processamento de interesse deste trabalho), desbloqueando a transformação de fase por relaxamento da rede cristalina ${ }^{(31)}$. Além disso, este tratamento térmico propicia a formação de precipitados ricos em Ni na matriz do material, empobrecendo-a em $\mathrm{Ni}$, ocasionando uma variação da relação $\mathrm{Ti} / \mathrm{Ni}^{(33)}$, levando assim a um aumento das temperaturas de transformação de fase, uma vez que o $\mathrm{Ni}$ é o elemento estabilizador da austenita a temperatura ambiente ${ }^{(34,35)}$. Na Tabela 4 são apresentadas as temperaturas de transformação de fase das juntas NiTi em todas as condições de soldagem. Para fins de comparação, foram inseridas as temperaturas de transformação de fase para o metal de base (MB) sem a realização de TTPS e para o MB com a realização de TTPS.

Para as condições $\mathrm{C} 1$ a $\mathrm{C} 4$ observou-se que $\mathrm{R}_{\mathrm{s}}$ atingiu temperaturas de início de transformação da ordem de $14^{\circ} \mathrm{C}$. Além disso, para maiores velocidades de soldagem houve uma redução da ordem de $2^{\circ} \mathrm{C}$ no valor de $\mathrm{R}_{\mathrm{s}}$. A grande concentração de calor

Tabela 4: Temperaturas das transformações de fase das juntas de LMF de NiTi soldadas pelo processo LBW.

\begin{tabular}{|c|c|c|c|c|c|c|}
\hline & $\mathbf{R}_{\mathbf{s}}\left({ }^{\circ} \mathbf{C}\right)$ & $\mathbf{R}_{\mathbf{f}}\left({ }^{\circ} \mathbf{C}\right)$ & $\mathbf{M}_{\mathbf{s}}\left({ }^{\circ} \mathbf{C}\right)$ & $\mathbf{M}_{\mathbf{f}}\left({ }^{\circ} \mathbf{C}\right)$ & $\mathbf{A}_{\mathbf{s}}\left({ }^{\circ} \mathbf{C}\right)$ & $\mathbf{A}_{\mathbf{f}}\left({ }^{\circ} \mathbf{C}\right)$ \\
\hline $\begin{array}{c}\text { MB sem } \\
\text { TTPS }\end{array}$ & $-13,7$ & & & & & \\
\hline C1 & 14,1 & - & - & - & - & - \\
\hline C2 & 12,5 & - & - & - & - & - \\
\hline C3 & 14,3 & - & - & - & - & - \\
\hline C4 & 12,3 & - & - & - & - & - \\
\hline MB com & 38,4 & 28,8 & $-28,1$ & $-46,9$ & 21,4 & 28,8 \\
\hline C5 & 37,2 & 24,5 & 0,4 & $-12,6$ & 36,2 & 43,3 \\
\hline C6 & 38,2 & 22,6 & 0,8 & $-7,5$ & 34,8 & 41,6 \\
\hline C7 & 34,9 & 22,6 & 1,9 & $-6,9$ & 35,9 & 40,8 \\
\hline C8 & 43,2 & 27,9 & 0,2 & $-10,7$ & 32,9 & 45,6 \\
\hline MB sem & $-13,7$ & & & & & \\
\hline TTPS & & & & & - \\
\hline C9 & 14,3 & - & - & - & - & - \\
\hline C10 & 12,2 & - & - & - & - & - \\
\hline C11 & 14,6 & - & - & - & - & - \\
\hline C12 & 12,6 & - & - & - & - & - \\
\hline MB com & 38,4 & 28,8 & $-28,1$ & $-46,9$ & 21,4 & 28,8 \\
\hline C13 & 37,6 & 24,5 & 0,3 & $-12,8$ & 36,4 & 43,8 \\
\hline C15 & 38,1 & 22,2 & 0,9 & $-8,0$ & 34,6 & 41,1 \\
\hline & 35,1 & 23,0 & 1,8 & $-7,1$ & 36,1 & 40,6 \\
\hline
\end{tabular}


na poça de fusão, característica intrínseca deste processo $^{(36)}$, intensificou o processo de volatilização de elementos de liga, além de favorecer a precipitação de compostos de $\mathrm{Ni}_{4} \mathrm{Ti}_{3}, \mathrm{Ni}_{3} \mathrm{Ti}_{2}$ e $\mathrm{Ni}_{3} \mathrm{Ti}$ durante o processo de solidificação ${ }^{(6,14)}$, criando a concorrência entre estes dois fenômenos e o de indução de defeitos metalúrgicos de soldagem ${ }^{(15)}$, que são os principais responsáveis por aumentar as temperaturas de transformação de fase do MS $\left(14^{\circ} \mathrm{C}\right)$ em relação ao $\mathrm{MB}\left(-13,7^{\circ} \mathrm{C}\right)$.

Já para as condições $\mathrm{C} 5$ a C8, as temperaturas início de transformação da fase R permaneceram praticamente idênticas ao MB com TTPS, isto é um indicativo que o TTPS homogeneizou o material. Além disso, o metal de solda destas juntas soldadas encontra-se em um estado misto, composto de austenita e fase R. Todas as condições de soldagem que foram submetidas ao TTPS apresentam o seguinte comportamento de transformação de fase: austenita para a fase $\mathrm{R}$ e transformação da fase $\mathrm{R}$ em martensita durante o resfriamento e transformação direta da martensita para a austenita durante o aquecimento, como já fora reportado ${ }^{(34)}$.

No entanto, a realização do TTPS não é a única solução tecnológica disponível para desbloquear as transformações de fase após a soldagem. Tuissi et al. (1999) ${ }^{(11)}$ avaliaram a influência dos tratamentos térmicos de pré-processamento, solubilização e envelhecimento, nas temperaturas de transformação de fase após a soldagem e verificou que ligas de NiTi quando solubilizadas e submetidas a soldagem apresentaram um aumento da temperatura de início de transformação martensítica $\left(\mathrm{M}_{\mathrm{s}}\right)$, devido à alta densidade de pontos de nucleação disponíveis para a formação da martensita. Além disso, a transformação observada parece ocorrer de maneira direta, da austenita para a martensita, suprimindo a existência da fase R. Já as ligas que foram envelhecidas e submetidas a soldagem não apresentaram fronteiras de distinção claras nas transformações de fase, averiguadas por DSC, indicando a presença da fase R. Portanto, o efeito que a soldagem induz nas temperaturas de transformação de fase depende do estado inicial da liga. Quando não se dispõe de meios de modificação da estrutura inicial da liga, o TTPS apresenta-se como alternativa viável, pois além de aliviar as tensões residuais de soldagem, pode-se adequar o tempo e a temperatura que o tratamento será realizado a fim de se obter a microestrutura e comportamento de interesse, além de desbloquear a transformação de fase devido ao trabalho mecânico de laminação para obtenção das chapas, eliminando assim a necessidade de realizar tratamento térmico antes da soldagem e outro após a execução da união ${ }^{(42)}$.

$\mathrm{Na}$ Fig. 7 estão apresentados os perfis de microdureza ao longo da seção transversal do cordão de solda e o box-plot das durezas no metal de solda.

O perfil de microdureza observado foi semelhante ao já extensamente reportado na literatura técnica vigente $\mathrm{e}^{(11,20,22,28,37,38)}$. A redução observada nos valores de microdureza no MS devese a presença de grãos colunares e aumento do tamanho de grão na região central do MS. As condições de soldagem submetidas ao TTPS também apresentaram uma ligeira redução nos valores médios de microdureza do MS. Esta redução ocorre devido ao fato que o TTPS ajuda a estabilizar a fase $\mathrm{R}$ ou a martensita, que são fases menos duras que a austenita ${ }^{(2)}$, a temperaturas próximas a ambiente. A Tabela 5 apresenta os valores médios de dureza no MS.

A microestrutura do metal de solda observada no processo LBW, conforme revela a Fig. 8, foi colunar com uma tímida ZTA de grãos equiaxiais. $\mathrm{O}$ crescimento do metal de solda se deu por epitaxia a partir do $\mathrm{MB}$, com grãos mais grosseiros no centro da solda e experimentando uma diminuição destes grãos à medida que se aproxima da linha de fusão. Em todas as condições de soldagem do processo LBW é possível notar a presença de uma região enegrecida na parte superior da junta. Trata-se de uma reação de oxidação do $\mathrm{Ti}$, uma vez que as juntas foram obtidas sem proteção gasosa.

$\mathrm{Na}$ Fig. 9 é apresentado o comportamento mecânico das juntas soldadas durante carregamento até $6 \%$ de deformação e subsequente descarregamento. As juntas soldadas que não sofreram TTPS apresentaram comportamento frágil, rompendo

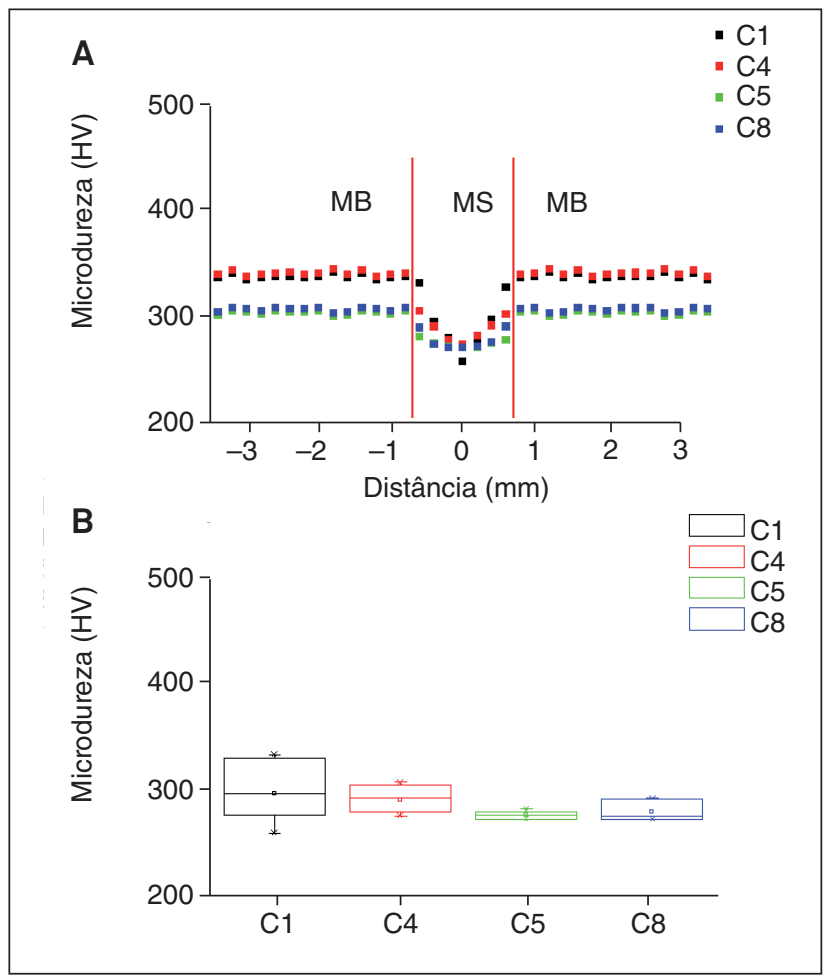

Figura 7: Perfil de microdureza ao longo da seção transversal das juntas soldadas (A) e o box-plot da dureza no MS (B) utilizando o processo LBW.

Tabela 5: Valores médios $(\mu)$ e desvios padrões $(\sigma)$ de microdureza no MS para as condições de soldagem C1, C4, C5 e C8.

\begin{tabular}{|c|c|c|c|c|c|c}
\multirow{2}{*}{} & \multicolumn{2}{|c|}{ Sem TTPS } & \multicolumn{2}{c|}{ Com TTPS } & \multirow{2}{*}{ Média } \\
\cline { 2 - 6 } & C1 & C4 & C5 & C8 & \\
\hline $\begin{array}{c}\mu \\
(\mathrm{HV})\end{array}$ & 295,0 & 289,4 & 274,7 & 277,9 & 284,3 \\
\hline $\begin{array}{c}\sigma \\
(\mathrm{HV})\end{array}$ & 27,3 & 12,2 & 3,8 & 8,8 & 9,6 \\
\hline
\end{tabular}


com deformações inferiores a $3 \%$ sem conseguir promover a indução de martensita por tensão. As condições de soldagem C5 e C6 apresentaram indução de martensita por tensão a uma tensão crítica de transformação de aproximadamente $470 \mathrm{MPa}$. Em ambos os casos, observou-se o laço tensão - deformação característico da superelasticidade resultante da indução da

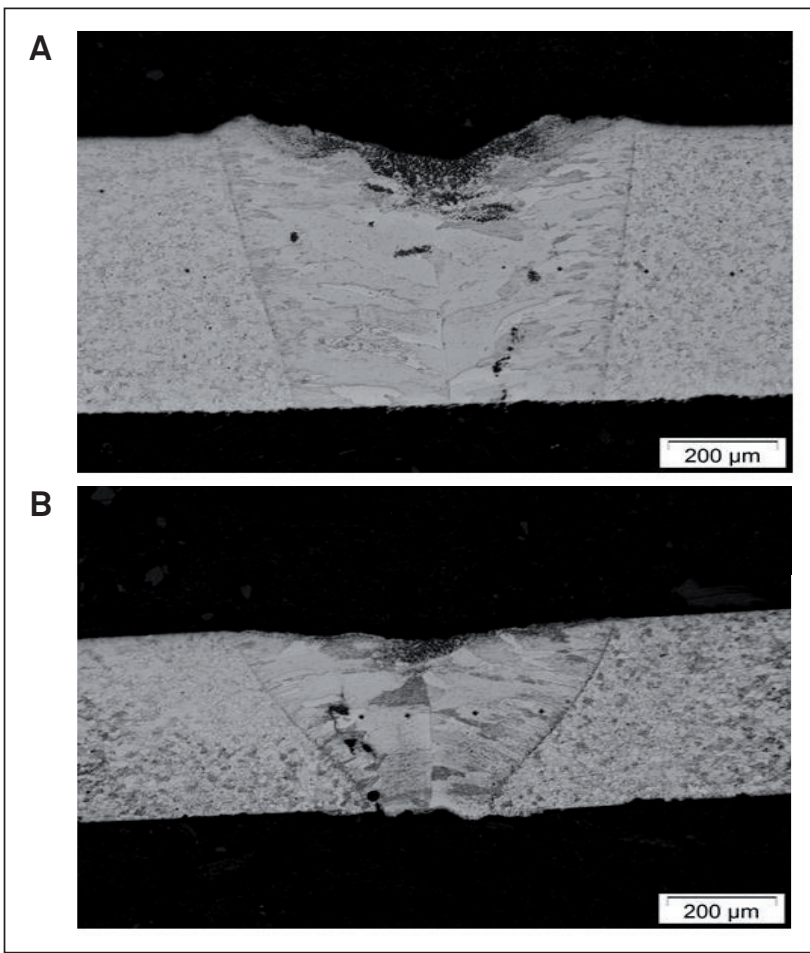

Figura 8: Microestruturas das juntas soldadas $C 1$ (A) e C4 (B).

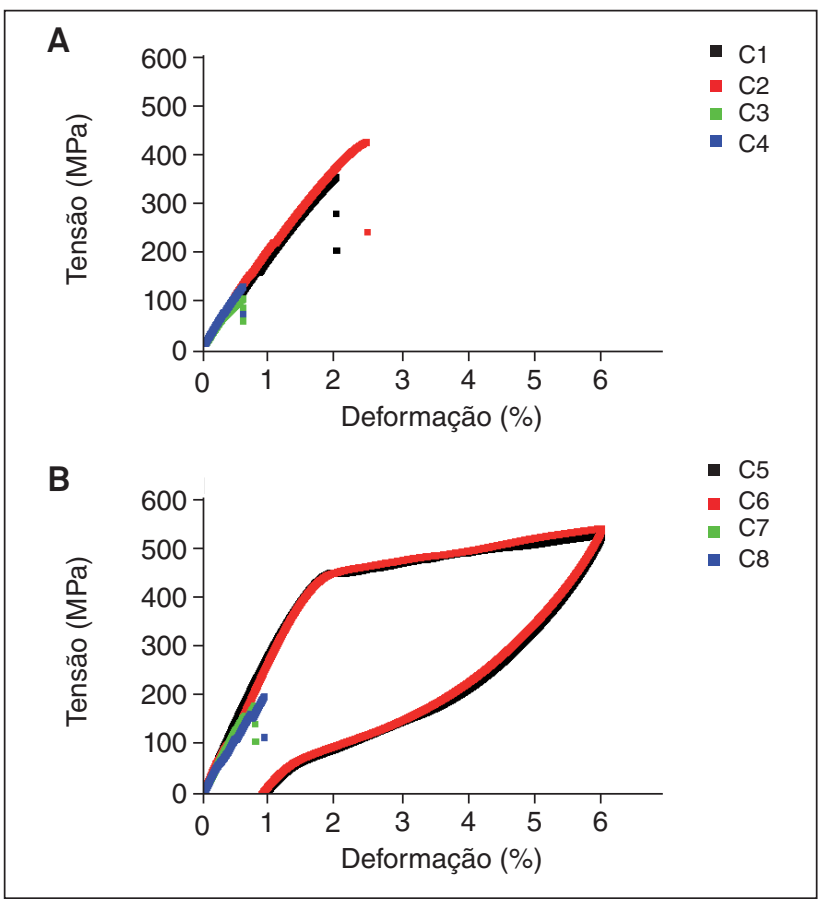

Figura 9: Comportamento mecânico das juntas soldadas de LMF de NiTi pelo processo LBW na condição "como soldado" (A) e após TTPS (B). martensita por tensão a partir da austenita. Nesses casos, a deformação residual observada após o descarregamento foi da ordem de $1 \%$. O comportamento frágil das juntas soldadas pode ser atribuído ao uso de velocidades de soldagem elevadas que não proporcionou a penetração total da junta, requisito primordial para se obter juntas íntegras e de elevada resistência, não sendo, portanto, recomendado este procedimento para a união de LMF de NiTi austeníticas, mesmo se estas juntas forem submetidas ao TTPS.

Na Fig. 10 é possível observar as curvas tensão - deformação até a ruptura para as condições de soldagem C5 e C6 após o primeiro ciclo de superelasticidade apresentado na Fig. 9b, enquanto que a Tabela 6 apresenta um resumo do limite de resistência $\left(\sigma_{\text {rup }}\right)$ e

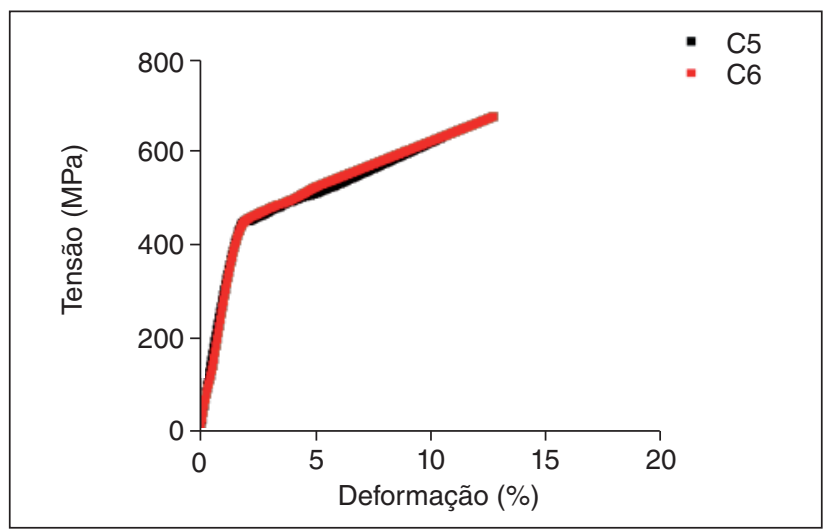

Figura 10: Curva tensão $x$ deformação para as juntas soldadas C5 e C6 após o primeiro ciclo de superelasticidade (Figura 9b).

Tabela 6: Resumo das propriedades mecânicas de todas as juntas de LMF de NiTi para as diferentes condições de soldagem.

\begin{tabular}{|c|c|c|}
\hline & $\boldsymbol{\sigma}_{\text {rup }}(\mathbf{M P a})$ & $\boldsymbol{\varepsilon}_{\text {tot }}(\%)$ \\
\hline MB & $\mathbf{7 7 3}$ & $\mathbf{2 0 , 1}$ \\
\hline C2 & 353 & 2,0 \\
\hline C3 & 424 & 2,5 \\
\hline C4 & 105 & 0,6 \\
\hline MBTT & 130 & 0,6 \\
\hline C5 & 541 & $\mathbf{2 0 , 3}$ \\
\hline C6 & 628 & 10,5 \\
\hline C7 & 675 & 12,8 \\
\hline C8 & 181 & 0,8 \\
\hline MB & 199 & 0,9 \\
\hline C9 & 773 & $\mathbf{2 0 , 1}$ \\
\hline C10 & 357 & 2,0 \\
\hline C11 & 428 & 2,5 \\
\hline C12 & 106 & 0,6 \\
\hline MBTT & 131 & 0,6 \\
\hline C13 & 541 & 20,3 \\
\hline C14 & 634 & 10,4 \\
\hline C15 & 682 & 12,7 \\
\hline C16 & 183 & 0,8 \\
\hline & 201 & 0,9 \\
\hline
\end{tabular}


máxima deformação suportada $\left(\varepsilon_{\text {tot }}\right)$. A partir destes dados foi possível realizar uma análise de variância dos resultados e identificar quais variáveis são estatisticamente significativas na união de LMF de NiTi e qual a influência de cada uma delas no comportamento mecânico da junta soldada. Na Tabela 7 é apresentado o nível de significância " $\alpha$ " dos fatores de controle estudados sobre o limite de resistência $\left(\sigma_{\text {rup }}\right)$ e máxima deformação suportada $\left(\varepsilon_{\text {tot }}\right)$. Níveis de significância menores que 0,05 indicam efeitos estatisticamente significativos, ou seja, há uma probabilidade de acerto de $95 \%$ em se admitir que este fator de controle esteja influenciando nas variáveis de resposta analisadas.

Na Tabela 7, $\mathrm{P}_{\mathrm{m}}(\mathrm{W}){ }^{*} \mathrm{~V}_{\mathrm{s}}(\mathrm{mm} / \mathrm{min}), \mathrm{P}_{\mathrm{m}}(\mathrm{W}){ }^{*}$ TTPS e $\mathrm{V}_{\mathrm{s}}(\mathrm{mm} /$ $\mathrm{min}){ }^{\star}$ TTPS representam interações entre os parâmetros de processo.

Tabela 7: Nível de significância dos fatores de controle do processo LBW sob as variáveis de resposta.

\begin{tabular}{|c|c|c|}
\hline Fatores & $\sigma_{\text {rup }}(\mathrm{MPa})$ & $\boldsymbol{\varepsilon}_{\text {tot }}(\%)$ \\
\hline Média & 0,000000 & 0,000000 \\
\hline $\mathrm{Pm}(\mathrm{W})$ & 0,000000 & 0,000000 \\
\hline $\mathrm{Vs}(\mathrm{mm} / \mathrm{min})$ & 0,000000 & 0,000000 \\
\hline TTPS & 0,000000 & 0,000000 \\
\hline $\mathrm{Pm}(\mathrm{W}){ }^{*}$ Vs & 0,000001 & 0,000000 \\
\hline$(\mathrm{mm} / \mathrm{min})$ & 0,000533 & 0,000000 \\
\hline $\mathrm{Pm}(\mathrm{W}){ }^{*}$ TTPS & 0,000000 & 0,000000 \\
\hline $\mathrm{Vs}(\mathrm{mm} / \mathrm{min}){ }^{*}$ TTPS & $99,98 \%$ & $99,78 \%$ \\
\hline $\mathrm{R}^{2}$ & $99,97 \%$ & $99,64 \%$ \\
\hline Adj & 7,84 & 0,001791 \\
\hline MS Erro Puro & & \\
\hline
\end{tabular}

Os modelos matemáticos empíricos, codificados, com seus respectivos parâmetros estatísticos, são apresentados nas Eqs. 1 e 2, tendo sido levados em consideração todos os efeitos estatisticamente significativos.

$$
\begin{aligned}
\sigma_{\text {rup }}(L B W) & =338,56+20,22 * P_{m}(W)-184,04 * V_{s}+ \\
& +84,24 * T T P S-9,42 * P_{m}(W) * T T P S- \\
& -3,89 * P_{m}(W) * V_{s}-47,86 * T T P S * V_{s} \\
\varepsilon_{\text {tot }}(L B W) & =3,81+0,36 * P_{m}(W)-3,09 * V_{s}+ \\
& +2,40 * T T P S+0,23 * P_{m}(W) * T T P S- \\
& -0,34 * P_{m}(W) * V_{s}-2,27 * T T P S * V_{s}
\end{aligned}
$$

Na Tabela 8 estão os resultados da análise de variância para todas as respostas. Os modelos além de estatisticamente significativos podem ser utilizados para fins preditivos, pois os valores de $\mathrm{F}_{\text {calc }}$ superam, e muito, os valores de $\mathrm{F}_{\text {tabelado }}{ }^{(39)}$.

As Figs. 11 a 16 apresentam a influência dos parâmetros de

\begin{tabular}{|c|c|c|c|c|c|}
\hline & & $\begin{array}{l}\text { Soma dos } \\
\text { Quadrados }\end{array}$ & $\begin{array}{l}\text { Graus de } \\
\text { Liberdade }\end{array}$ & $\begin{array}{l}\text { Quadrados } \\
\text { Médios }\end{array}$ & $F_{\text {calc }}$ \\
\hline \multirow{3}{*}{ 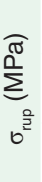 } & Regressão & 700486,0 & 6 & 116748,0 & \multirow{3}{*}{7743,0} \\
\hline & Resíduo & 135,7 & 9 & 15,078 & \\
\hline & Total & 700622,0 & 15 & 116763,0 & \\
\hline \multirow{3}{*}{$\overbrace{\omega^{\circ}}^{\widehat{\varrho}}$} & Regressão & 333,3 & 6 & 55,5 & \multirow{3}{*}{685,2} \\
\hline & Resíduo & 0,73 & 9 & 0,08 & \\
\hline & Total & 334,04 & 15 & 55,65 & \\
\hline
\end{tabular}
soldagem no limite de resistência e máxima deformação suportada pelas juntas de LMF de NiTi para as condições de soldagem do processo LBW.
Tabela 8: Análise de variância (ANOVA) para o limite de resistência e a máxima deformação suportada.

$\mathrm{F}_{6,9}=3,37$

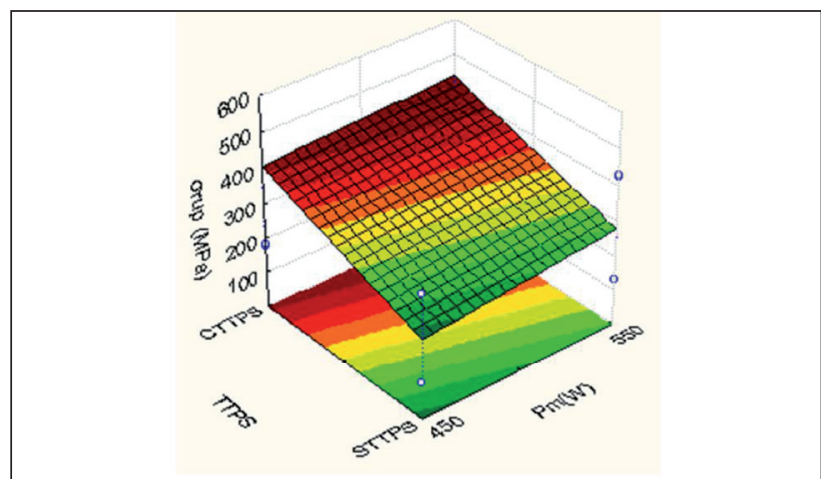

Figura 11: Influência da potência média e do TTPS sobre o limite de resistência das juntas soldadas.

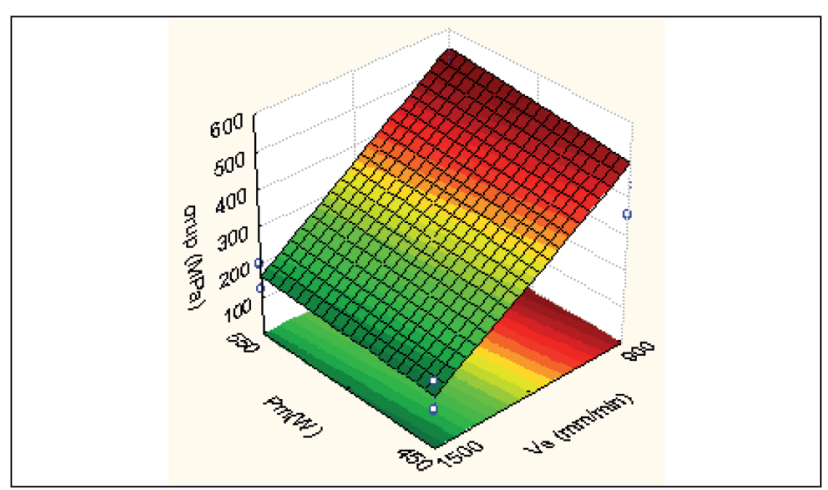

Figura 12: Influência da potência média e da velocidade de soldagem sobre o limite de resistência das juntas soldadas.

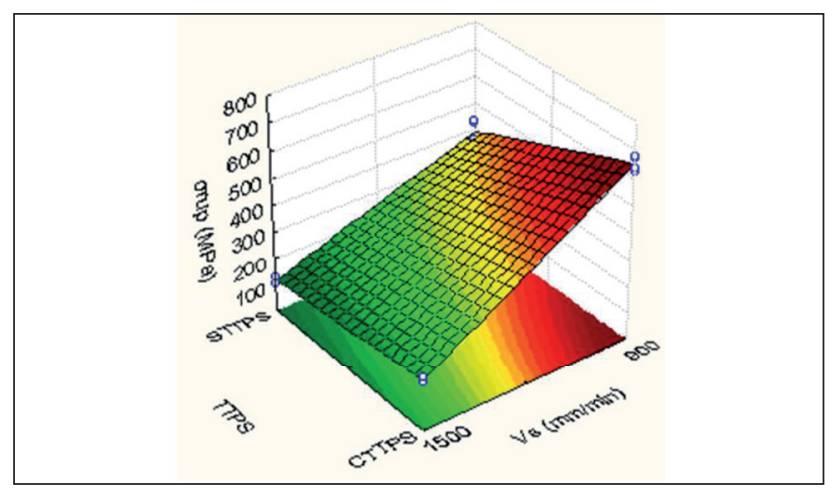

Figura 13: Influência do TTPS e da velocidade de soldagem sobre o limite de resistência das juntas soldadas. 


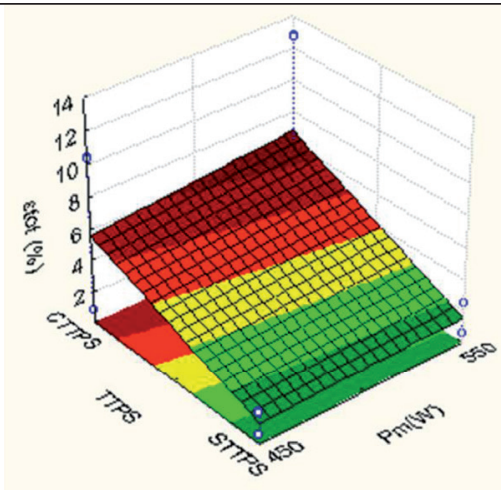

Figura 14: Influência da potência média e do TTPS sobre a máxima deformação suportada pelas juntas soldadas.

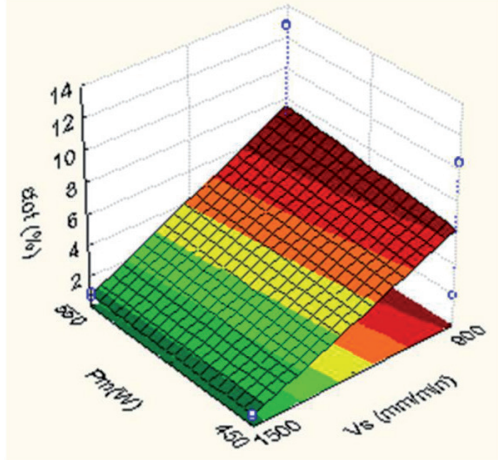

Figura 15: Influência da potência média e da velocidade de soldagem sobre a máxima deformação suportada pelas juntas soldadas.

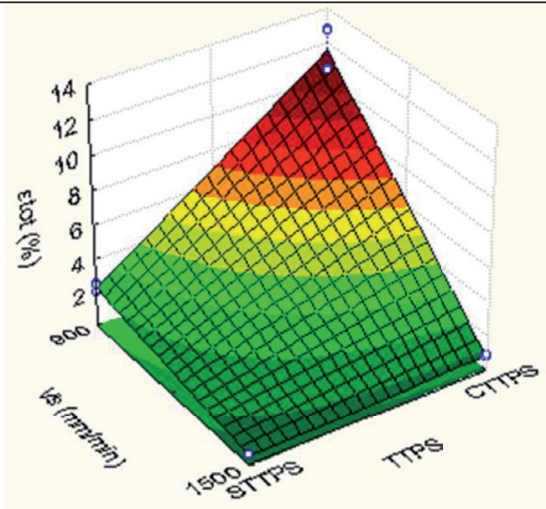

Figura 16: Influência do TTPS e da velocidade de soldagem sobre a máxima deformação suportada pelas juntas soldadas.

As juntas soldadas pelo processo LBW que foram submetidas ao TTPS apresentaram-se mais resistentes que àquelas que não foram submetidas a esta operação, ou seja, as juntas soldadas de ligas austeníticas de NiTi pelo processo LBW mandatoriamente têm de ser submetidas ao TTPS, sob pena de não apresentar a resistência mecânica mínima para que o fenômeno da superelasticidade seja observado. Além disso, a potência média de soldagem aplicada não promoveu ganhos significativos da resistência da junta soldada, como pode ser observado na Fig. 11. Vale salientar ainda que as juntas soldadas com elevada velocidade de soldagem, cerca de $1500 \mathrm{~mm} / \mathrm{min}$, não apresentaram resistência mecânica satisfatória, conforme revelado na Fig.12, tendo em vista que a energia de soldagem diminui fortemente para esta faixa de velocidade de soldagem promovendo a fragilização da junta soldada devido a precipitação de fases frágeis e principalmente falta de penetração total da junta soldada. Portanto, as juntas soldadas de ligas austeníticas de NiTi pelo processo LBW devem ser executadas a velocidades de soldagem de cerca de $900 \mathrm{~mm} / \mathrm{min}$ e sofrerem TTPS, sempre com potência média da ordem de 550 W, conforme Fig. 13.

As juntas soldadas que foram submetidas ao TTPS suportaram maiores deformações que aquelas que não foram submetidas a tal operação. Ainda é possível observar que a potência média de soldagem empregada também não promoveu aumentos significativos da deformação suportada e que as juntas que foram soldadas com menores velocidades de soldagem foram capazes de suportar maiores deformações, como pode ser observado nas Figs. 14 a 16.

A Tabela 9 apresenta um resumo dos melhores resultados observados na literatura técnica nacional e internacional comparados com os resultados obtidos neste trabalho.

Pode-se observar que os resultados obtidos neste trabalho são bastante superiores àqueles da maioria dos outros trabalhos observados na literatura técnica, suportando grandes deformações a níveis de tensões elevadas, como as juntas soldadas obtidas por Sevilla et al. ${ }^{(40)}$, apresentando apenas desempenho inferior a Mirshekari et al. $)^{(28)}$.

As Figs. 17 e 18 indicam o local onde foram realizadas as aferições por EDS da composição química no interior de vazios observados na superfície de fratura das condições de soldagem C1 e C5. As Tabelas 10 e 11 apresentam a composição química da região obtida por ensaio de EDS.

Pode-se verificar um grande desvio composicional nesta região, corroborando com a hipótese de Holsberg ${ }^{(42)}$ e Trevisan

Tabela 9: Comparativo entre as propriedades mecânicas em tração melhor condição de soldagem obtida neste trabalho e aquelas obtidas por diversos autores.

\begin{tabular}{|c|c|c|c|c|}
\hline Geometria & $\begin{array}{c}\text { Condição de } \\
\text { Soldagem }\end{array}$ & $\begin{array}{c}\boldsymbol{\sigma}_{\text {rup }} \\
(\mathbf{M P a})\end{array}$ & $\begin{array}{c}\boldsymbol{\varepsilon}_{\text {tot }} \\
(\%)\end{array}$ & Referência \\
\hline Fio & $\mathrm{IM}=119 \mathrm{~A}$ & 325 & 5,0 & $(5)$ \\
\hline Chapa & $\mathrm{PM}=910 \mathrm{~W}$ & 498 & 10,44 & $(20)$ \\
\hline Chapa & $\mathrm{PM}=850 \mathrm{~W}$ & 520 & 7,0 & $(6)$ \\
\hline Fio & $\mathrm{PM}=100 \mathrm{~W}$ & 620 & 8,0 & $(16)$ \\
\hline Fio & $\mathrm{PM}=2,5 \mathrm{~W}$ & 350 & 12,0 & $(40)$ \\
\hline Fio & $\mathrm{PM}=1000 \mathrm{~W}$ & 835 & 16,0 & $(28)$ \\
\hline Chapa & $\mathrm{Não} \mathrm{informado}$ & 823 & 8,4 & $(38)$ \\
\hline Chapa & $\mathrm{PM}=77 \mathrm{~W}$ & 690 & 8,8 & $(22)$ \\
\hline Chapa & $\mathrm{PM}=600 \mathrm{~W}$ & 300 & 8,0 & $(41)$ \\
\hline Chapa & $\mathrm{PM}=1,3 \mathrm{~kW}$ & 600 & 11,0 & $(19)$ \\
\hline Fio & $\mathrm{IM}=110$ & 187 & 11,0 & $(29)$ \\
\hline Chapa & $\mathrm{PM}=1,5 \mathrm{~kW}$ & 450 & 5,1 & $(30)$ \\
\hline Chapa & $\mathrm{PM}=550 \mathrm{~W}$ & 682 & 12,7 & Este Trabalho \\
\hline & & & & \\
\hline
\end{tabular}


et al. ${ }^{(43)}$ de que os vazios formados durante a solidificação das ligas de Ti são gerados em função da queda drástica da solubilidade

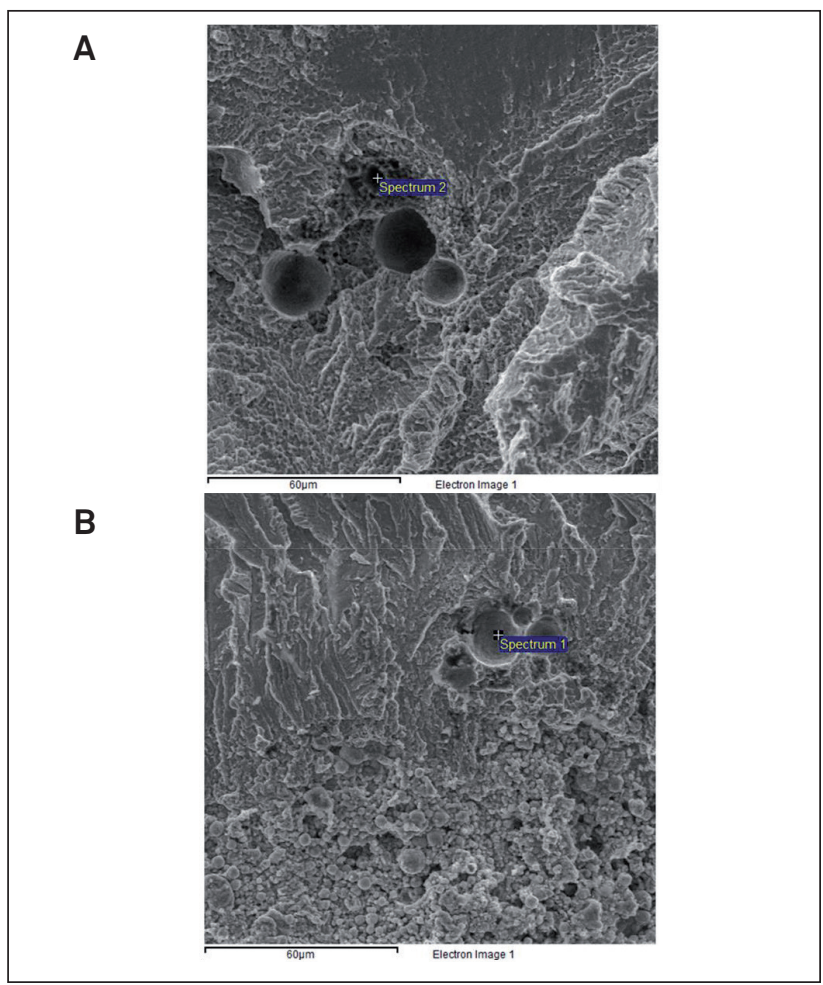

Figura 17: Imagens de MEV indicando os locais onde foram realizadas as avaliações de EDS no interior de um vazio na condição de soldagem C1 (A) e C5 (B).

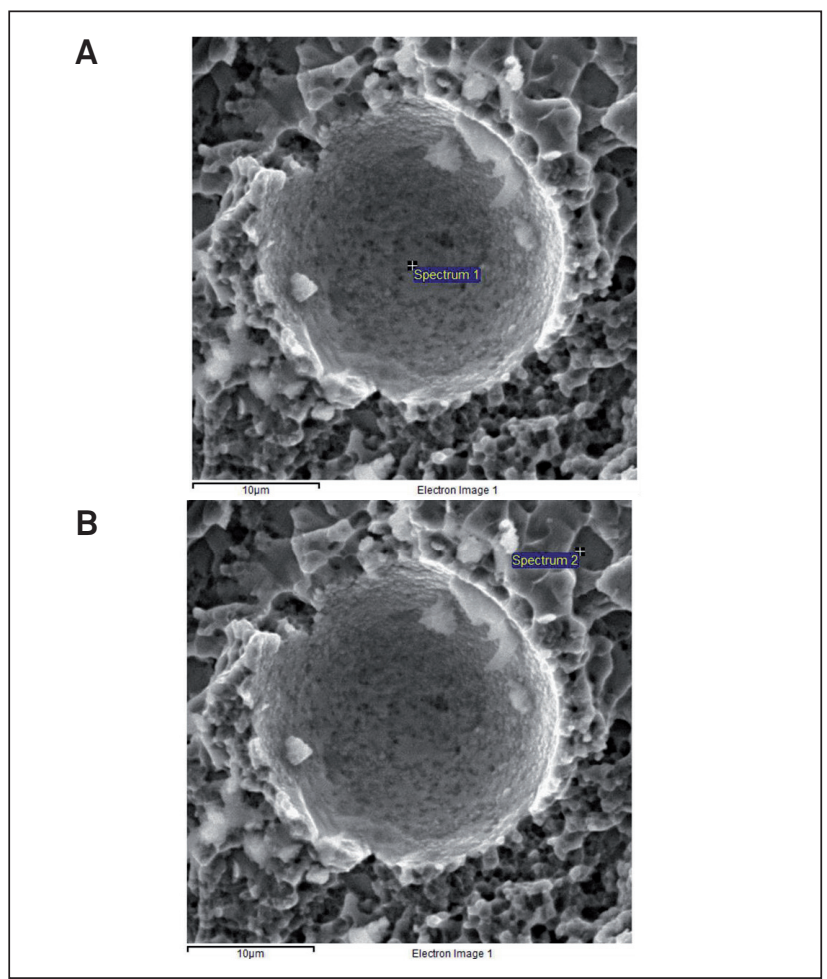

Figura 18: Imagens de MEV indicando os locais onde foram realizadas as avaliações de EDS na superfície de um vazio $(A)$ e na superfície de fratura (B) da condição de soldagem C7. do $\mathrm{H}, \mathrm{N}$ e $\mathrm{O}$ atômico no MS, fazendo com que estes compostos intersticiais se dissociem e migrem entre as dendritas de $\beta$-Ti, e formem $\mathrm{H}, \mathrm{N}$ e O molecular, provocando então segregação de Ti na região em seu entorno.

A partir da Fig. 18 e da Tabela 11 é possível afirmar que variação composicional citada anteriormente ocorre na periferia/ interface do defeito e que em condições normais de solidificação do MS a composição química volta ao equilíbrio original, com leve volatilização de $\mathrm{Ni}$.

No processo LBW as juntas soldadas C1 e C4 (Figs. 19a e 19d) apresentaram aspecto pouco dúctil. Já as condições de soldagem C5 e C6 (Figs. 19e e 19f) apresentaram superfície de fratura com a presença de dimples planos e com relevo acentuado, indicando maior ductilidade se comparada as demais, enquanto que as condições de soldagem C7 e C8 (Figs. 19g e 19h) apresentam pontos claros que possivelmente são óxidos no MS, devido à ausência de gás de proteção na soldagem destas juntas, e ao comportamento pirofórico observado destas quando das soldagens prospectivas utilizando argônio como gás de proteção, fragilizando-as.

Tabela 10: Composição química na superfície de fratura das condições de soldagem C1 e C5.

\begin{tabular}{|c|c|c|c|}
\hline & Elemento & \% em peso & \% atômica \\
\hline \multirow{0}{*}{$\overline{0}$} & Ti K & 62,46 & 67,10 \\
& Ni K & 37,54 & 32,90 \\
\hline \multirow{3}{*}{$\mathcal{O}$} & Total & 100,00 & \\
\hline & Ti K & 64,68 & 69,18 \\
& Ni K & 35,32 & 30,82 \\
\hline
\end{tabular}

Tabela 11: Composição química na superfície de fratura da condição de soldagem C7.

\begin{tabular}{|c|c|c|c|}
\hline & Elemento & $\%$ em peso & \% atômica \\
\hline \multirow{3}{*}{ 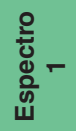 } & TiK & 58,01 & 62,87 \\
\hline & $\mathrm{Ni} \mathrm{K}$ & 41,99 & 37,13 \\
\hline & Total & 100 & \\
\hline \multirow{3}{*}{ 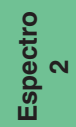 } & TiK & 47,44 & 52,52 \\
\hline & $\mathrm{Ni} \mathrm{K}$ & 52,56 & 47,48 \\
\hline & Total & 100 & \\
\hline
\end{tabular}

\section{CONCLUSÕES}

Por meio das técnicas do planejamento experimental fatorial e da superfície de resposta foi possível compreender a influência dos parâmetros de soldagem na resistência mecânica das juntas soldadas e, assim, determinar os melhores parâmetros de soldagem para a união das chapas de LMF NiTi (austeníticas) pelo processo LBW (uniões com potência média de 550W e velocidade de soldagem de $900 \mathrm{~mm} / \mathrm{min}$, submetida a TTPS).

$\mathrm{O}$ ensaio não destrutivo de RET aplicado pela primeira vez em uma junta soldada de LMF nesta pesquisa foi capaz 

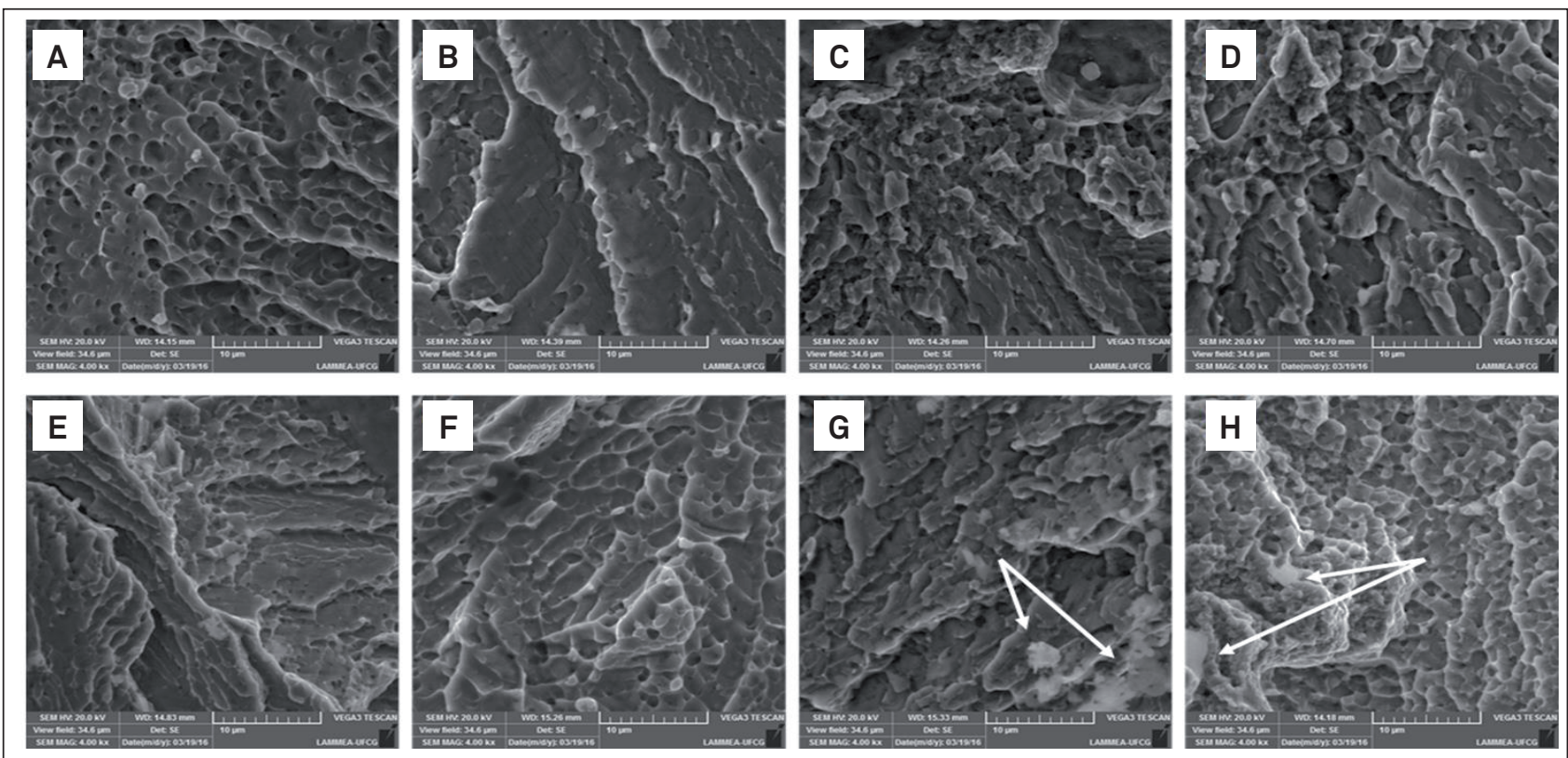

Figura 19: Aspecto das superfícies de fratura de todas as condições de soldagem com 4000 vezes de aumento, da esquerda para a direita partindo de $\mathrm{C} 1$ até $\mathrm{C} 8$.

de indicar que para as juntas soldadas de ligas austeníticas de NiTi a soldagem aumentou as temperaturas de início de transformação da fase $\mathrm{R}$, mas não foi capaz de "desbloquear completamente" a transformação da fase. Ou seja, na condição "como soldado" as juntas permaneceram no estado austenítico a temperatura ambiente, de aproximadamente $25^{\circ} \mathrm{C}$. Para esta chapa, que é mais rica em Ni, o TTPS foi responsável por fazer aparecer a transformação de fase na faixa de temperatura de $-60^{\circ} \mathrm{C}$ a $50^{\circ} \mathrm{C}$, aumentando todas as temperaturas de transformação devido a depreciação característica do $\mathrm{Ni}$ durante tratamentos térmicos a temperaturas próximas de $500^{\circ} \mathrm{C}$. Após o TTPS as juntas soldadas das chapas austeníticas de NiTi encontravam-se em um estado misto composto de austenita e fase R. Portanto, é possível afirmar que o TTPS é de fundamental importância na soldagem de LMF austeníticas de NiTi, pois é responsável por fazer aparecer a transformação de fase na faixa de temperatura de interesse e garantir que o comportamento funcional da pseudoelasticidade possa ser observado.

Os ensaios de tração conduzidos a temperatura ambiente revelaram que as juntas soldadas das chapas de LMF de NiTi austeníticas foram capazes de suportar deformações da ordem de 63,0\% com relação a deformação máxima suportada pelo MB sem solda. É notório que o processo de soldagem é responsável por diminuir a resistência mecânica das juntas soldadas em função da baixa penetração durante a soldagem e eventualmente da precipitação de fases frágeis no MS e na ZTA

Quanto ao aspecto da superfície de fratura as juntas soldadas de LMF austeníticas de NiTi na condição "como soldado" apresentaram modo de fratura dúctil com a presença de microdimples, enquanto que as juntas soldadas que foram submetidas ao TTPS apresentaram o modo de fratura dúctil conhecido como TTS.

\section{AGRADECIMENTOS}

Os autores agradecem ao CNPq pelo financiamento dos projetos Casadinho UFCG-UFRJ-ITA (Processo no 552199/2011-7), Universal 14/2012 (Processo no 474524/2012-4), CT-Aeroespacial 22/2013 (Processo no 402082/2013-3) e PQ 1D (Processo no 304658/2014-6), e a CAPES pelo auxílio financeiro e bolsas.

\section{REFERENCES}

1. RICE, C. Shape Memory Alloys, Applications. In: Encyclopedia of Smart Materials. Freemont: John Wiley \& Sons, 2002.

2. OTSUKA, K.; WAYMAN, C. M. Shape Memory Materials. Cambridge University Press, 1998. ISBN 0-521-44487-X.

3. LAGOUDAS, D. Shape Memory Alloys: Modeling and Engineering Applications. Springer, 2008. ISBN 978-0-387-47685-8.

4. CHAN, C. W.; MAN, H. C. Reduction of environmentally induced cracking of laser-welded shape memory NiTi wires via post-weld heat-treatment. Materials Science and Engineering A, v. 588, p.388-394, 2013a.

5. SONG, Y.G.; LI, W.S.; LI, L.; ZHENG, Y. F. The influence of laser welding parameters on the microstructure and mechanical property of the as-joined NiTi alloy-wires. Materials Letters, v. 62, p.2325-2328, 2008.

6. FALVO, A. FURGIUELE, F. M. MALETTA, C. Laser Welding of a NiTi Alloy: Mechanical and Shape Memory Behaviour. Materials Science and Engineerin A, v. 412, p. 235-240, 2005. 
7. POUQUET, J.; MIRANDA, R. M.; QUINTINO, L. Dissimilar laser welding of NiTi to Stainless Steel. International Journal of Advaced Manuf. Technology, v. 61, p.205-212, 2012.

8. MAN, H. C.; ZHAO, N. Q. Enhancing the adhesive bonding strength of NiTi shape memory alloys by laser gas nitriding and selective etching. Applied Surface Science, v. 253, p.1595-2000, 2006.

9. YAN, X. J.; YANG, D. Z.; LIU, X. P. Corrosion behavior of a laserwelded NiTi shape memory alloy. Materials Characterization, v. 58, p.623-628, 2007a.

10. HSU, Y. T.; WANG, Y. R.; WU, S. K.; CHEN, C. Effect of CO2 laser welding on the shape-memory and corrosion characteristics of TiNi alloys. Metallurgical and Materials Transactions A, v. 32A, p.569-576, 2011

11. TUISSI, A.; BESSEGHINI, S.; RANUCCI, T.; SQUATRITO, F.; POZZI, M. Effect of Nd:YAG laser welding on the functional properties of the Ni-49.6 at.\%Ti. Materials Science and Engineering A, v. 273, p. $813-817,1999$

12. YAN, X. J.; YANG, D. Z.; QI, M. Rotating-bending fatigue of a laserwelded superelastic NiTi alloy wire. Materials Characterization, v. 57, p.68-63, 2006a

13. YAN, X. J.; YANG, D. Z.; LIU, X. P. Electrochemical behavior of YAG laser-welded NiTi shape memory alloy. Transactions of Nonferrous Metals Society of China, v. 16, p.572-576, 2006b.

14. YAN, Z.; CUI, L.; ZHENG, Y. Microstructure and martensitic transformation behaviors of explosively welded NiTi/NiTi Laminates. Chinese Journal of Aeronautics, v. 20, p.168-171, 2007b.

15. YAN, X. J.: YANG, D. Z.; LIU, X. P. Influence of heat treatment on the fatigue life of a laser welded NiTi alloy wire. Materials Characterization, v. 58, p.262-266, 2007c.

16. GUGEL, H. SCHUERMANN, A. THEISEN, W. Laser Welding of NiTi Wires. Materials Science and Engineering A, v. 481, p. 668-671, 2008.

17. ZHAO, X. K.; WANG, W.; CHEN, L.; LIU, F.; CHEN, G.; HUANG, J.; ZHANG. H. Microstructures of cerium added laser weld of a NiTi alloy. Materials Letters, v. 62, p.1551-1553, 2008a.

18. ZHAO, X. K.; WANG, W.; CHEN, L.; LIU, F.; CHEN, G.; HUANG, J.; ZHANG. H. Two-stage superelasticity of a Ce-added laser-welded TiNi alloy. Materials. Letters, v. 62, p.3539-3541, 2008b.

19. ZHAO, X. K.; LAN, L.; SUN, H.; HAUNG, J. H.; ZHANG, H.; WANG, Y. Mechanical properties of additive laser welded NiTi alloy. Materials Letters, v. 64, p.628-631, 2010.

20. ALBERTY VIEIRA, L.; FERNANDES, F. M.; MIRANDA, R. M.; SILVA, R. J. C.; QUINTINO, L.; CUESTA, A.; OCAÑA, J. L. Mechanical behaviour of Nd:YAG laser welded superelastic NiTi. Materials Science and Egineering A, v. 528, p.5560-5565, 2011.

21. GONG, W. H.; CHEN, Y. H.; KE LI, L. M. Microstructure and properties of micro welded joint of TiNi shape memory alloy. Transactions of nonferrous Metals Society of China, v. 21, p.20442048, 2011

22. CHAN, C. W. MAN, H. C. YUE, T. M. Effects of Process Parameters Upon The Shape Memory and Pseudo-Elastic Behaviors of LaserWelded NiTi Thin Foil. Metallurgical and Materials Transactions A, v. 24, p. 2264-2270, 2011.

23. CHAN, C. W. MAN, H. C. YUE, T. M. Effect of post-weld heattreatment on the oxide film and corrosion behaviour of laser- welded shape memory NiTi wires. Corrosion Science, v. 56, p.158167, 2012a.

24. CHAN, C. W. MAN, H. C. YUE, T. M. Susceptibility to stress corrosion cracking of NiTi laser weldments in Hank's solution. Corrosion Science, v. 57, p.260-269, 2012b.

25. CHAN, C. W. MAN, H. C. YUE, T. M. Susceptibility to enviromentally induced cracking of laser-welded NiTi wires in Hank's solution at open-circuit potential. Materials Science and Engineering A, v. 544, p.38-47, 2012c

26. CHAN, C. W.; MAN, H. C.; CHENG, F. T. Fatigue behavior of laserwelded NiTi wires in small-strain cyclic bending. Materials Science \& Engineering A, v. 559, p.407-415, 2013b

27. QUINTINO, L.; MIRANDA, R. M. Welding Shape Memory Alloys with Nd: YAG Lasers. Soldagem \& Inspeção, v. 17, p.210-217, 2012

28. MIRSHEKARI, G. R.: SAATCHI, A: KERMANPUR, A. SADRNEZHAAD, S. K. Laser welding of NiTi shape memory alloy: comparison of the similar and dissimilar joints to AISI 304 stainsless steel. Optics and Laser Technology, v. 54, p.151-158, 2013.

29. ZENG, Z.; YANG, M.; OLIVEIRA, J. P.; SONG, D.; PENG, B. Laser welding of NiTi shape memory alloy wires and tubes for multifunctional design applications. Smart Materials and Structures, v. 25, p.1-11, 2016

30. WANG, W.; YANG, X.; LI, H.; CONG, F.; LIU, Y. Effect of laser welding parameters on formation of NiTi shape memory alloys welds. Advances in Materials Science and Engineering, v. 2014 p.1-8, 2014

31. DeLOBELLE, V.; DELOBELLE, P.; LIU, Y.; LOUCHE, H. Resistance welding of NiTi shape memory alloy tubes. Journal of Materials Procesing Technology, v. 213, p.1139-1145, 2013.

32. LUKÁS, P.; SITTNER, P.; LUGOVOY, D.; NEOV, D.; CERETTI, M. In situ nêtron diffraction studies of the R-phase transformation in the NiTi shape memory alloy. Applied Physics A: Materials Science and Processing, v. 74, p.S1121-S1123, 2002.

33. TAM, B. Micro-Welding of Nitinol Shape Memory Alloy. 2010. 96f Dissertação (Mestrado em Engenharia Mecânica). Programa de Pós-graduação em Engenharia Mecânica, University of Waterloo, Waterloo - Ontario, Canadá.

34. ZHENG, Y.; JIANG, F.; LI, L.; YANG, H.; LIU, Y. Effect of ageing treatment on the transformation behaviour of Ti-50.9 at.\% Ni alloy. Acta Materialia, v. 56, p. 736-745, 2008

35. JIANG, F.; LIU, Y.; YANG, H.; LI, L.; ZHENG, Y. Effect of ageing treatment on the deformation behaviour of Ti-50.9 at.\% Ni. Acta Materialia, v. 57, p.4773-4781, 2009.

36. AMERICAN WELDING SOCIETY. Welding Handbook Volume 5 Materials and Applications - Part 2. AWS, 2015a. ISBN 978-087171-856-3.

37. AMORIM, F. A. Comportamento termomecânico de fios superelásticos de NiTi soldados pelo processo TIG. 2014. 112f. Dissertação (Mestrado em Engenharia Mecânica). Programa de Pós-graduação em Engenharia Mecânicca, Universidade Federal de Campina Grande - UFCG, Campina Grande - PB.

38. SCHLOSSMACHER, P.; HASS, T.; SCHUSSLER, A. Laser-Welding of a Ni-Rich TiNi Shape Memory Alloy: Mechanical Behavior. Journal de Physique IV, v. 4, p.251-256, 1997.

39. RODRIGUES, M. I.; IEMMA, A. F. Planejamento de Experimentos \& Otimização de Processos. Cárita Editora, 2009. ISBN 85-9838903-X. 
40. SeVILLA, P.; MARTORELL, F.; LIBENSON, C.; PLANELL, J. A.; GIL, F. J. Laser Welding of NiTi Orthodontic Archwires for Selective Force Application. Journal of Materials Science: Materials Medical, v. 19, p 525-529, 2008

41. KHAN, M. I.; PANDA, S. K.; ZHOU, Y. Effects of welding parameters on the mechanical performance of laser welded nitinol. Materials Transactions, v. 49, p.2702-2708, 2008.
42. HOLSBERG, P. W. Cracking and Porosity in Titanium and Titanium Alloy Weldments, DTNSRRDC Report, United States Navy. 1979.

43. TREVISAN, R. E.; SCHWEMMER, D. D.; OLSON, D. L. The Fundamentals of Weld Pore Formation In: OLSON, D. L (Ed.). Welding: Theory and Practice, New York: Elsevier, 1990. p79-115. 